\title{
EFFECTS OF THERMAL FATIGUE ON LASER MODIFIED H13 DIE STEEL
}

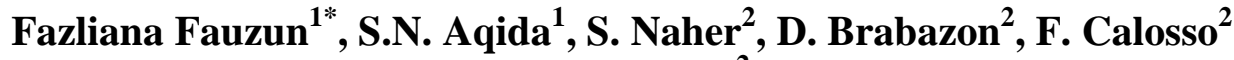 \\ and M. Rosso ${ }^{2}$ \\ ${ }^{\mathbf{1}}$ Faculty of Mechanical Engineering, University of Malaysia Pahang \\ 26600 Pekan, Pahang, Malaysia \\ *Email: fazlianafauzun@gmail.com \\ Phone : +609-424-2246; Fax : +609-424-2202 \\ ${ }^{2}$ Advanced Processing Group, Dublin City University, Dublin Ireland
}

\begin{abstract}
In order to improve the wear properties of $\mathrm{H} 13$ die steel, the thermal fatigue properties of AISI H13 tool steel were investigated at a varied number of cycles for enhancing surface hardness. $\mathrm{A} \mathrm{CO}_{2}$ laser system was used with a $0.09 \mathrm{~mm}$ focused spot size on the sample surface. The peak power of $1137 \mathrm{~kW}$ and pulse repetition frequency (PRF) of $2300 \mathrm{~Hz}$ were the parameters controlled. The Nabertherm model of a thermal fatigue machine used consisted of the cylindrical high temperature furnace with digital control panel, controlled temperature quenching system and pneumatics control sample movement mechanism. The samples were immersed in molten aluminum and quenched in ionized water emulsion at $17^{\circ} \mathrm{C}$ temperature within a specific time per cycle. The quenching system was equipped with a thermocouple to control the water temperature. The testing was done on 1,750 and 3,500 cycles. The treated samples was characterized for metallographic study and hardness. The metallographic study was conducted using an optical microscope for laser modified layer thickness and grain size and the hardness properties were measured using a Vickers indenter. Erosion occurred from the sample after 3500 cycles. The hardness of the laser treated layer was lowered, after a thermal fatigue test, from $650 \mathrm{HV}_{0.1}$ to $510 \mathrm{HV}_{0.1}$. These findings are important for designing high wear resistant surfaces through laser surface modification for applications forming semi-solid dies.
\end{abstract}

Keywords: Thermal fatigue; laser surface treatment; H13 tool steel.

\section{INTRODUCTION}

Cyclic high temperature conditions and exposure to high viscosity molten metal are among the causes of dies that wear and crack in semi-solid processing $(\mathrm{Xu}, \mathrm{Li}, \mathrm{Zhu}$, Liu, \& Liu, 2006). Thermal fatigue causes heat checking, which is one of most important life-timing tool failure mechanisms in molten metal die casting (Persson, Hogmark, \& Bergström, 2005). These die surface cracks cause unwanted marks or fins on the casting surface thus affecting the quality of end products (Ali, Mustapa, Ghazali, Sujitno, \& Ridha, 2013; Domínguez Almaraz, Guzmán Tapia, Tapia Silva, \& Cadenas Calderón, 2010; Klobčar, Kosec, Kosec, \& Tušek, 2012). Molten metals such as aluminum, zinc, magnesium and copper based alloys were exposed to thermal fatigue cracking resulting from rapid changes in the surface temperature. The application of pressure at high temperature during injection and a mold that was rapidly cooled within the order of milliseconds may induce stresses high enough to impose an increment of plastic strain in tool surfaces during each casting cycle (Aqida, Calosso, Brabazon, 
Naher, \& Rosso, 2010). Other failure modes that limit life and performance are gross fracture, erosion, corrosion and local adherence of casting alloy which also known as soldering (Persson et al., 2005). Surface engineering of borides, carbides and nitrides creates ceramic compounds with increased hardness, wear resistance and chemical inertness. It has been proven that surface engineering improves the wear resistance of tool materials in die casting (Klobčar, Tušek, \& Taljat, 2008). However, the mechanisms behind thermal fatigue cracking of a surface engineered material are still not fully explored (Klobčar et al., 2012). Surface modification techniques such as plasma vapor deposition, brush plating, plasma surface metallurgy technology and chemical vapor deposition are widely used in fabricating high wear resistance, oxidation resistance and corrosion resistance coating. (Batista et al., 2005). The materials used for surface coating may show different resistances against thermal cracking as compared to reference materials and the mechanism behind the thermal fatigue failure of coating surfaces are still not fully explored. Difficulties meeting the effective coating requirement caused surface treatment are more preferable in protecting dies from premature failure (Tsai, Lee, \& Chang, 2007; Xu et al., 2006).

Laser surface treatment is an unconventional but emerging manufacturing process. One of most relevant laser surface treatment processes is surface hardening on die materials. Laser hardening operates through a high intensity laser radiation source that heats the steel surface rapidly to the austenitic region (Avilés, Albizuri, Lamikiz, Ukar, \& Avilés, 2011). It is possible to modify the structural steels or alloy steel surface to enhance the mechanical properties. The treated layer results in increased hardness due to the formation of finer grains, secondary carbide and hard nonequilibrium microstructures (Aqida et al., 2010). Previous researchers have made predictions based on theory of the die in-service lifetime and damage mechanisms either in real production or in the laboratories. Thermal fatigue tests include the isothermal fatigue test, thermo-mechanical fatigue tests and thermal fatigue test in different variants (Charde, 2013; Klobčar et al., 2012; Klobčar et al., 2008; Tong, Dai, \& Zhang, 2013; Tong, Li, Liu, Dai, \& Zhou, 2010). In this study, H13 tool steel was laser treated and under went a thermal fatigue test to investigate thermal fatigue properties in die applications. Characterization was made using a Vickers harness tester and metallographic study.

\section{EXPERIMENTAL DETAILS}

An AISI H13 tool steel with the chemical composition given in Table 1 was investigated. The sample geometry was machined to an outer diameter of $33 \mathrm{~mm}$, and inner diameter of $22 \mathrm{~mm}$ length to fit the fatigue testing machine. All samples were laser treated with a Rofin DC-015 diffusion-cooled $\mathrm{CO}_{2}$ slab laser system with $10.6 \mu \mathrm{m}$ wavelength. The laser beam spot size was $0.09 \mathrm{~mm}$. The process parameters are given in Table 2. The laser spot traverse was calculated based on the PRF to allow uniform distribution distance between spots with $0 \%$ overlap. The scanning speed was $261 \mathrm{~mm} / \mathrm{s}$. The experiment was conducted in the presence of argon gas.

The schematic diagram of the fatigue testing machine is shown in Figure 1. The thermal fatigue machine test consists of a Naberthem cylindrical high temperature furnace with digital control panel, controlled temperature quenching system and pneumatics control sample movement mechanism. Samples were immersed in molten aluminum alloy at $850^{\circ} \mathrm{C}$ and quenched in ionized water emulsion at $17^{\circ} \mathrm{C}$ temperature for 4 seconds in each cycle to imitate the semi-solid forming process. The cycle was 
repeated 1,750 and 3500 times. A single cycle required 28 seconds to complete. Samples S2 and S3 represent the 1,750 cycle and 3,500 cycle respectively, and the S1 sample did not undergo the thermal fatigue test. Samples were cleaned using an $\mathrm{NaOH}$ solution after a thermal fatigue test to remove oxides on the sample surface. The solution temperature and stirring speed were set to $100^{\circ} \mathrm{C}$ and $4.5 \mathrm{rpm}$ respectively.

Table 1. The chemical compositions of AISI H13 tool steel.

\begin{tabular}{|c|c|c|c|c|c|c|c|c|c|c|c|}
\hline Element & $\mathrm{C}$ & $\mathrm{Mn}$ & $\mathrm{Si}$ & $\mathrm{Cr}$ & $\mathrm{Ni}$ & Mo & $\mathrm{V}$ & $\mathrm{Cu}$ & $\mathrm{P}$ & $\mathrm{S}$ & $\mathrm{Fe}$ \\
\hline $\mathrm{wt} \%$ & $\begin{array}{c}0.32- \\
0.45\end{array}$ & $\begin{array}{c}0.20- \\
0.50\end{array}$ & $\begin{array}{c}0.80- \\
1.20\end{array}$ & $\begin{array}{c}4.75- \\
5.50\end{array}$ & 0.3 & $\begin{array}{c}1.10- \\
1.75\end{array}$ & $\begin{array}{c}0.80- \\
1.20\end{array}$ & 0.25 & 0.03 & 0.03 & bal \\
\hline
\end{tabular}

Table 2. Laser parameters for sample S1, S2 and S3 AISI H13 tool steel.

\begin{tabular}{cccccccc}
\hline $\begin{array}{c}\text { Peak } \\
\text { Power } \\
(\mathrm{W})\end{array}$ & $\begin{array}{c}\text { PRF } \\
(\mathrm{Hz})\end{array}$ & $\begin{array}{c}\text { Duty } \\
\text { Cycle } \\
(\%)\end{array}$ & $\begin{array}{c}\text { Pulse } \\
\text { Width, } \tau \\
(\mathrm{s})\end{array}$ & $\begin{array}{c}\text { Scanning } \\
\text { Speed,v } \\
(\mathrm{mm} / \mathrm{min})\end{array}$ & $\begin{array}{c}\text { Energy } \\
(\mathrm{J} / \mathrm{mm})\end{array}$ & $\begin{array}{c}\text { Residence } \\
\text { Time, } \\
(\mathrm{ms})\end{array}$ & $\begin{array}{c}\text { Irradiance } \\
(\mathrm{W} / \mathrm{mm} 2)\end{array}$ \\
\hline 1137.5 & 2300 & 24.1 & $1.05^{-4}$ & 207 & 0.12 & $1.05^{-4}$ & 178,804 \\
\hline
\end{tabular}

Metallographic study and hardness measurement were conducted on cross sections of the modified surface. IM7000 Series Inverted Optical microscopes with Progress Capture 28.8 Jenoptik Optical System image analyzer software were used for imaging purposes. Hardness properties of were measured using MMT Matsuzawa Vickers Hardness tester with a 10kgf load.

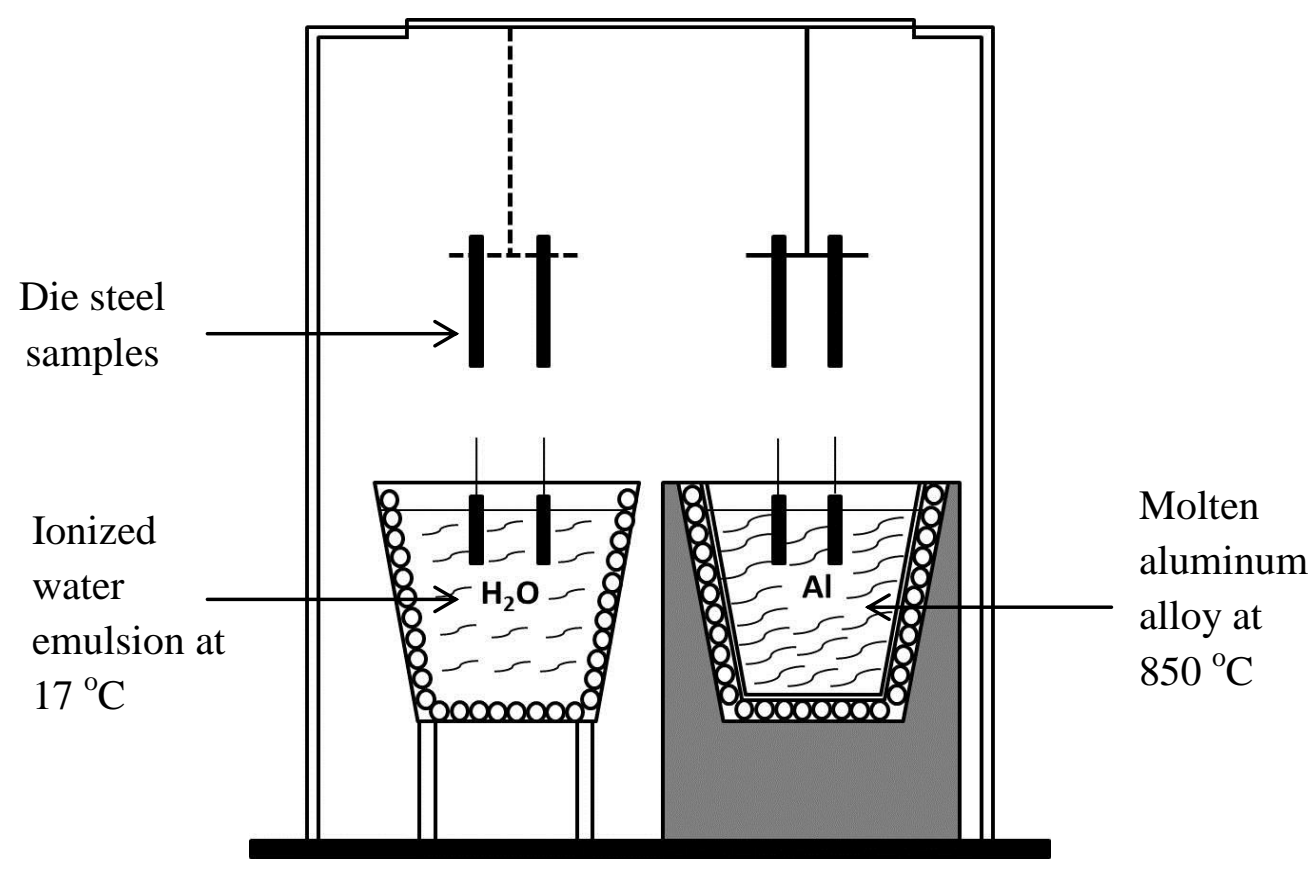

Figure 1. The schematic diagrams of thermal fatigue testing machine (Aqida et al., 2010; Klobčar et al., 2012). 


\section{RESULTS AND DISCUSSION}

\section{Metallographic study}

The micrographs in Figure 1 show the cross-section of laser modified samples S1 (without thermal fatigue test), S2 and S3 which were tested for thermal fatigue at 1,750 and 3,500 cycles respectively. In Sample 1, the modified layer thickness was $168 \mu \mathrm{m}$ and Sample 2 was $160 \mu \mathrm{m}$. An average modified layer depth of $128 \mu \mathrm{m}$ was measured in Sample 3. Slight erosion was detected on the steel surface after 1,750 and 3,500 cycles of thermal fatigue test which decreased the depth of the laser treated layer. H13 hot work tool steel is commonly used for semi solid casting die materials. High harden ability and tolerance with thermal shock resistance are an added advantages of die materials (Aqida et al., 2010) However, dies in the aluminum casting process operate at the temperature of secondary hardening or even at higher temperatures.

In thermal fatigue testing, the sample surface expands during heating and shrinks during cooling (Tong et al., 2010). In certain conditions, hardening may occur at early cycles but very soon a general softening prevails. The stages of softening started with a dislocation density reduction, continued with a quasi-stationary softening by carbide evolution and finally, drastic stress reduction occurs which results in erosion and cracking (Klobčar et al., 2012). The treated surface layer does not alter the appearance of the surface strain because they are controlled by deformation of substrate material during heat cycling (Persson et al., 2005). The treated layers may be too thin to have any notable effect on temperature distribution below the surface.

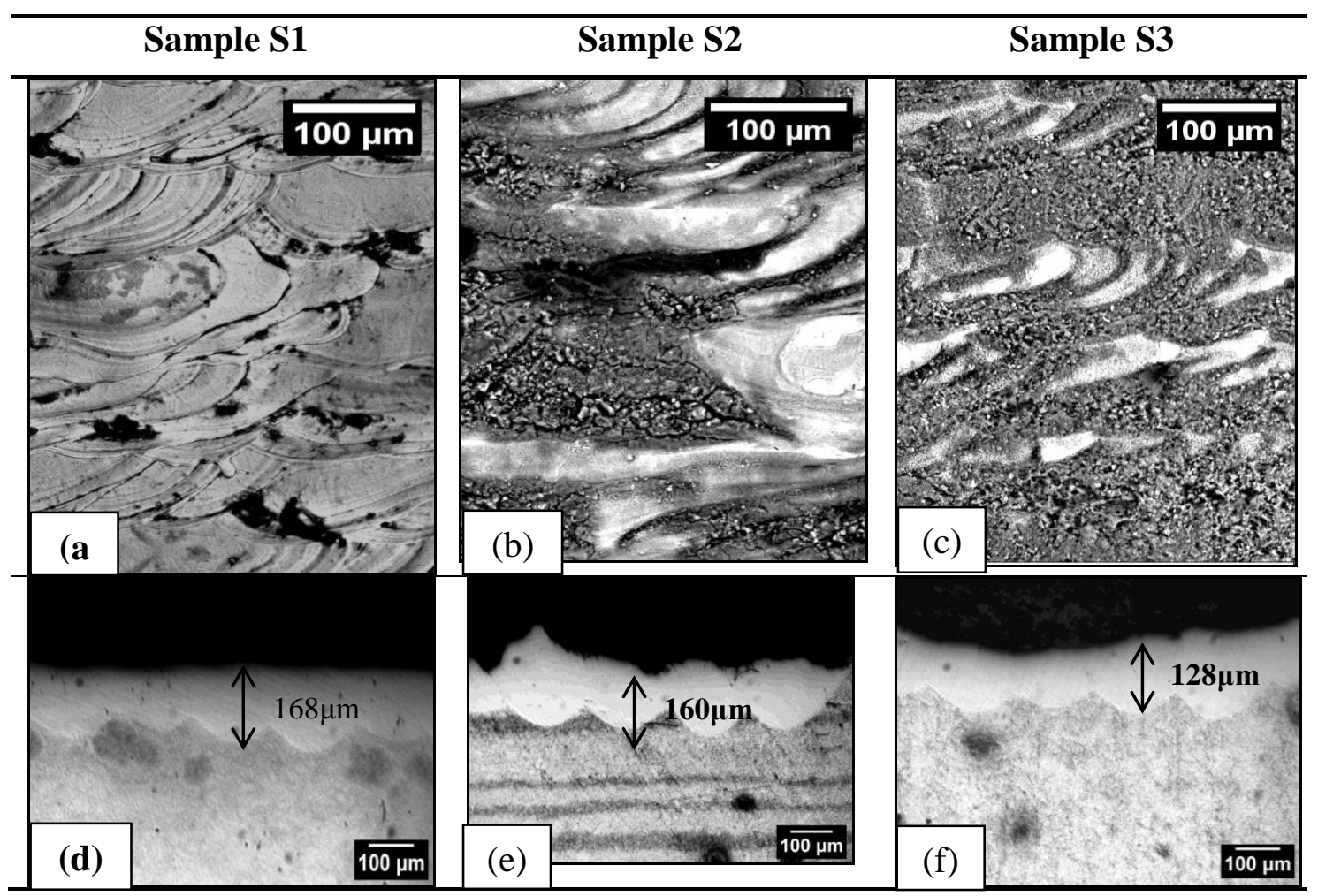

Figure 1.Morphology and cross-section of sample S1 (a and d) before thermal fatigue test, sample S2 (b and e) and sample S3 (c and f) after thermal fatigue test at 1,750 and 3,500 cycles. 


\section{Hardness Properties}

The hardness properties of all samples cross-sectional are plotted in Figure 2. Samples $\mathrm{S} 2$ and S3 represent different hardness at 1,750 cycles and 3,500 cycles respectively, and sample S1 was without thermal fatigue test. A significant decrease in hardness was observed across the number of cycles. After 1,750 cycles, the hardness of Sample 2 was decreased to an average of $560 \mathrm{HV}_{0.1}$ compared to $\mathrm{S} 1$, with average hardness of 650 $\mathrm{HV}_{0.1}$. Sample S3 which underwent a thermal fatigue test of 3,500 cycles had the lowest hardness of $510 \mathrm{HV}_{0.1}$. Decreased hardness in these sample tests was the result of surface tempering due to high temperature testing. It may also have been caused by thermal fatigue during cyclic loading or aging during immersion testing (Klobčar et al., 2008). Typically, for $700^{\circ} \mathrm{C}$ experiments the hardness of the $0.3-1 \mathrm{~mm}$ surface layer decreased during thermal cycling for all test materials. Below this depth the materials are unaffected by cyclic heat exposures (Persson et al., 2005). In this study, the $850^{\circ} \mathrm{C}$ experiments resulted in hardness reduction as shown in Figure 2. The greater hardness on laser treated layers decreased the potential of steel softening and thus delayed thermal fatigue.

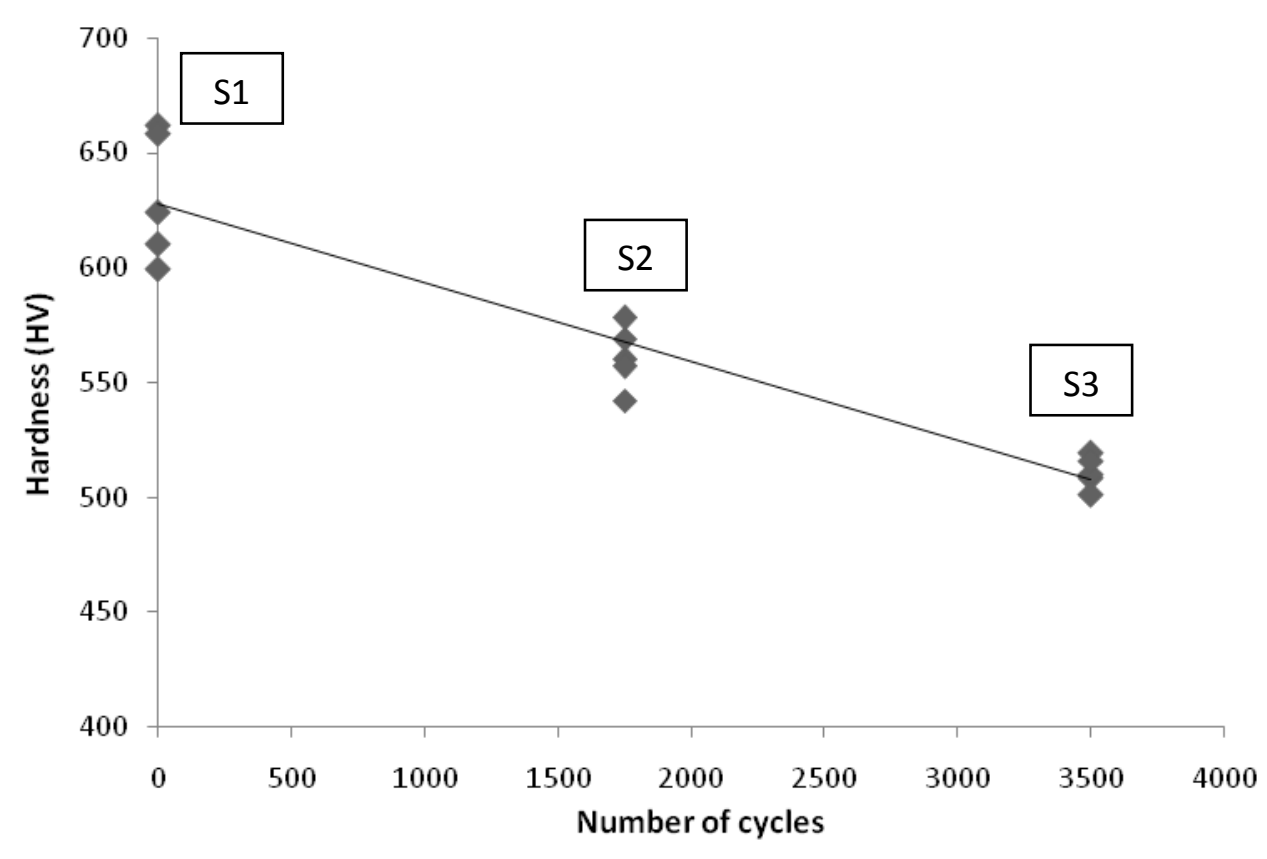

Figure 2. Hardness properties of laser modified samples before and after thermal fatigue at 1,750 and 3,500 cycles.

\section{CONCLUSIONS}

Material erosion occurred on samples that experienced 3,500 cycles of thermal fatigue which resulted in a decreased laser treated surface layer. At the same laser parameter setting, a significant hardness decrease between the tested and untested samples were clearly observed. The increased hardness of the laser treated layer fell after a thermal fatigue test from an average hardness of $650 \mathrm{HV}_{0.1}$ to $510 \mathrm{HV}_{0.1}$. High temperature during cyclic loading resulted in compressive stress thus causing a plastic deformation of the surface. The life of a die casting can be extended with the use of harder, more ductile and tougher materials which can resist the tempering and aging process. The 
findings of this study are significant for enhancing thermal fatigue properties in semisolid processing.

\section{ACKNOWLEDGEMENTS}

The authors would like to thank the University of Malaysia Pahang and the Ministry of Higher Education Malaysia for financial support under the RDU120105 Fundamental Research Grant Scheme.

\section{REFERENCES}

Ali, N., Mustapa, M. S., Ghazali, M. I., Sujitno, T., \& Ridha, M. (2013). Fatigue life prediction of commercially pure titanium after nitrogen ion implantation. International Journal of Automotive and Mechanical Engineering, 7, 10051013.

Aqida, S. N., Calosso, F., Brabazon, D., Naher, S., \& Rosso, M. (2010). Thermal fatigue properties of laser treated steels. Springer-Verlag France, 1, 797-800.

Avilés, R., Albizuri, J., Lamikiz, A., Ukar, E., \& Avilés, A. (2011). Influence of laser polishing on the high cycle fatigue strength of medium carbon aisi 1045 steel. International Journal of Fatigue, 33(11), 1477-1489.

Batista, C., Portinha, A., Ribeiro, R., Teixeira, V., Costa, M., \& Oliveira, C. (2005). Surface laser-glazing of plasma-sprayed thermal barrier coatings. Applied Surface Science, 247(1), 313-319.

Charde, N. (2013). Microstructure and fatigue properties of dissimilar spot welds joints of aisi 304 and aisi 1008. International Journal of Automotive and Mechanical Engineering, 7, 882-899.

Domínguez Almaraz, G. M., Guzmán Tapia, M., Tapia Silva, E. E., \& Cadenas Calderón, E. (2010). Fatigue life prediction based on macroscopic plastic zone on fracture surface of aisi-sae 1018 steel. International Journal of Automotive and Mechanical Engineering, 1, 29-37.

Klobčar, D., Kosec, L., Kosec, B., \& Tušek, J. (2012). Thermo fatigue cracking of die casting dies. Engineering Failure Analysis, 20, 43-53.

Klobčar, D., Tušek, J., \& Taljat, B. (2008). Thermal fatigue of materials for die-casting tooling. Materials Science and Engineering: A, 472(1), 198-207.

Persson, A., Hogmark, S., \& Bergström, J. (2005). Thermal fatigue cracking of surface engineered hot work tool steels. Surface and Coatings Technology, 191(2), 216227.

Tong, X., Dai, M.-j., \& Zhang, Z.-h. (2013). Thermal fatigue resistance of h13 steel treated by selective laser surface melting and crni alloying. Applied Surface Science, 271, 373-380.

Tong, X., Li, F.-h., Liu, M., Dai, M.-j., \& Zhou, H. (2010). Thermal fatigue resistance of non-smooth cast iron treated by laser cladding with different self-fluxing alloys. Optics \& Laser Technology, 42(7), 1154-1161.

Tsai, P.-C., Lee, J.-H., \& Chang, C.-L. (2007). Improving the erosion resistance of plasma-sprayed zirconia thermal barrier coatings by laser glazing. Surface and Coatings Technology, 202(4), 719-724.

Xu, J., Li, Z., Zhu, W., Liu, Z., \& Liu, W. (2006). The comparative study of thermal fatigue behavior of laser deep penetration spot cladding coating and brush plating ni-w-co coating. Applied Surface Science, 253(5), 2618-2624. 